\title{
Hereditary palmoplantar keratoderma, Gamborg-Nielsen type
}

INSERM

\section{Source}

INSERM. (1999). Orphanet: an online rare disease and orphan drug data base. Hereditary palmoplantar keratoderma, Gamborg-Nielsen type. ORPHA:86923

Hereditary palmoplantar keratoderma, Gamborg-Nielsen type is characterised by the presence of diffuse palmoplantar keratoderma without associated symptoms. The syndrome has been described in multiple families from the northernmost county of Sweden (Norrbotten). The palmoplantar keratoderma found in the Gamborg-Nielsen type disease is milder than that found in Mal de Meleda but more severe than that found in Thost-Unna palmoplantar keratoderma (see these terms). Transmission is autosomal recessive. 